\title{
Historical
}

Pẹspective

\section{Ignác Semmelweis and the Etiology of Fetal and Neonatal Sepsis}

\section{Tonse N. K. Raju, MD}

It is well known that Ignác Semmelweis discovered the etiology and prophylaxis of puerperal sepsis. However, few historians have focused on his understanding of the pathophysiology of fetal and neonatal sepsis. Based on several key observations, Semmelweis realized that puerperal fever (also known as "childbed fever") could be transmitted to the fetus, especially when the first stage of labor was prolonged and multiple examiners performed vaginal examinations while their fingers were contaminated. This insight was particularly valuable in that it helped him decipher the mystery of puerperal sepsis. This paper presents some of these concepts and supporting evidence.

\section{"... but, chance only favors the prepared mind ..."} -Louis Pasteur ${ }^{1}$

In 1847, a young Hungarian obstetrician, Ignác Semmelweis (1818 to 1865), discovered the etiology and prophylaxis of puerperal sepsis. Medical historians have correctly noted that the turning point in this discovery was Semmelweis' reading of the autopsy findings of his professor, Jakob Kolletschka, who had died of sepsis. $^{2-4}$

But, a study of his entire work ${ }^{5}$ (Figure 1) reveals that an additional factor also played a major part in Semmelweis' discovery. It was his logical analysis of fetal and neonatal sepsis and mortality data that prepared him to correctly interpret Kolletschka's autopsy findings. This paper provides evidence in support of this argument.

\section{Biographical Sketch and the Discovery of the Etiology of Puerperal Sepsis}

Ignác (also spelled Ignaz) was born in Tabán, a section in today's Budapest. After graduating in medicine in 1844, he completed obstetric training and became an assistant to Professor Johann Klein at the Lying-in-Hospital of Vienna, where he worked for 3 years, except for 5 months break during the winter of 1846 to

The Division of Neonatology, Department of Pediatrics, University of Illinois at Chicago, IL. Address correspondence and reprint requests to Tonse N. K. Raju, MD, Department of Pediatrics, Mail Code 856, University of Illinois at Chicago, 840 South Wood St., Chicago, IL 60612.
1847. This hospital was one of the largest European teaching institutions for students in medicine and midwifery, with over 6000 annual deliveries. Since 1840, because of overcrowding and increasing enrollment, the medical students were assigned exclusively to the larger First Division and the midwifery students, to the smaller Second Division.

Semmelweis soon noted the high maternal mortality resulting from puerperal fever (often called "childbed fever") in the First Division (Figure 2,A). He became convinced that the riddle of childbed fever could be solved only through understanding the cause of the mortality differentials. A striking difference in routine practice was that doctors and medical students in the First Division, before starting

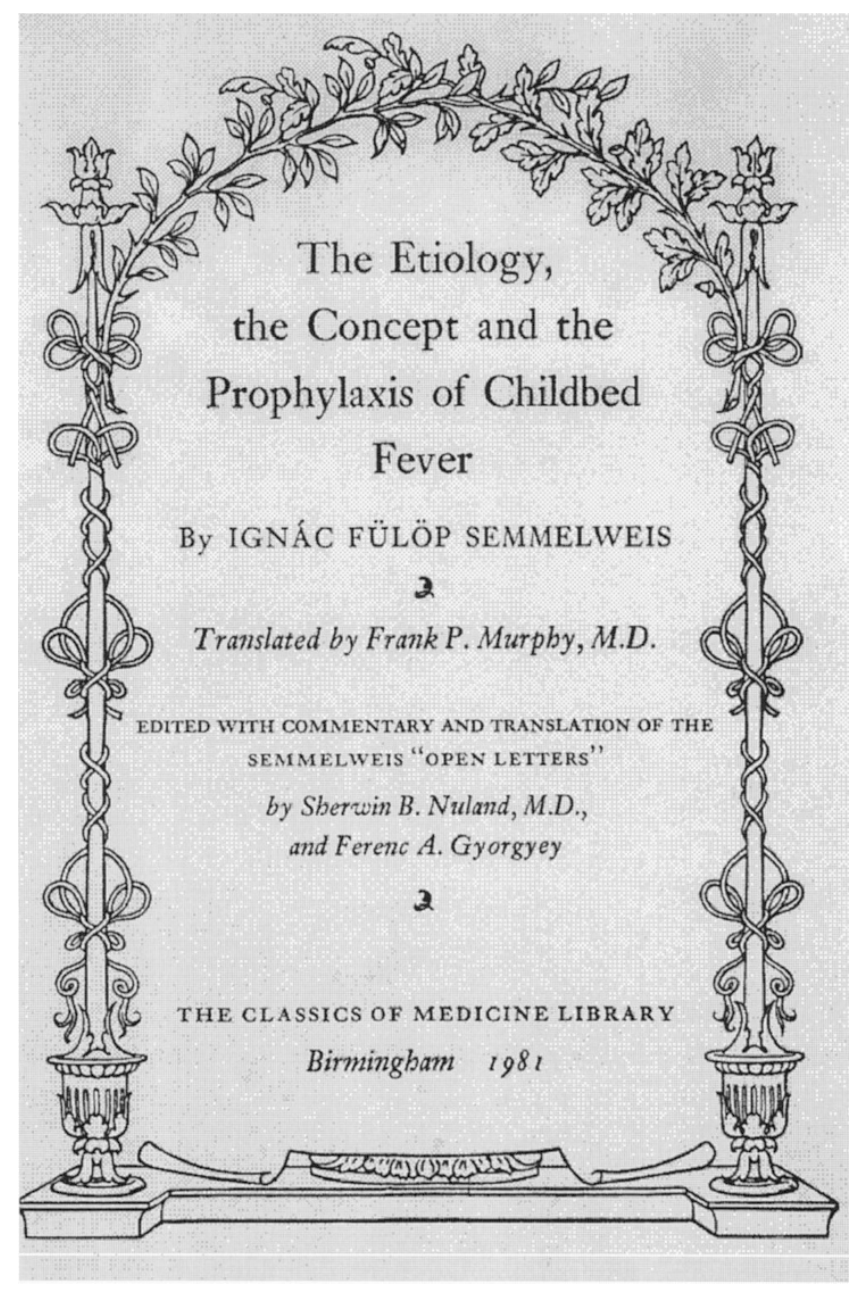

Figure 1 The title page of Semmelweis' book published in 1861. [Reproduced with permission from The Classics of Medicine Library; Birmingham, AL.] 


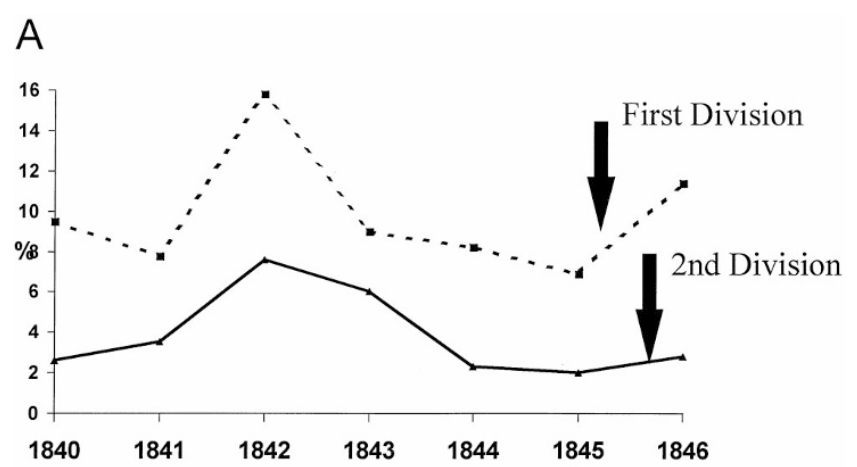

Years

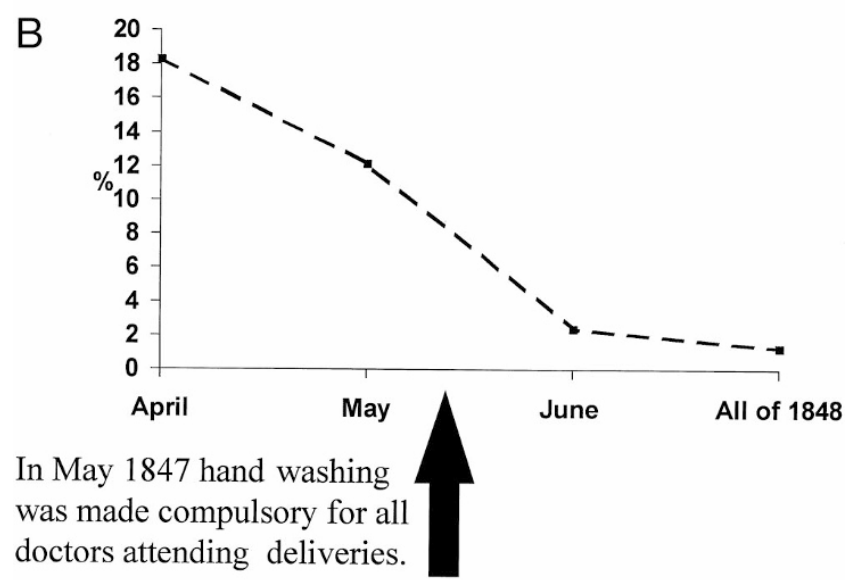

Figure 2 Maternal mortality from childbed fever in the two divisions of the Lyingin-Hospital before the introduction of routine hand washing (A) and after (B).

their daily clinical duties in the maternity ward, were required to perform autopsies on women who had died the previous night. The midwifery students in the Second Division were not required to perform autopsies.

In March 1847, Jakob Kolletschka, a professor in forensic pathology, died of sepsis from an accidental finger wound sustained during an autopsy. While mourning, Semmelweis read the autopsy findings of his professor and was astonished to note its similarities to that of the victims of childbed fever. Later he would write:

"... suddenly a thought crossed my mind: childbed
fever and the death of Professor Kolletschka were one
and the same. ... His ... sepsis and childbed fever
must originate from the same source. [The cause]
was to be found in the fingers and hands of students
and doctors, soiled by recent dissections ... [and
they] ... carry those death-dealing cadavers' poisons
into the genital organs of women in childbirth....."

After experimenting on various cleansing agents to get rid of the stench and "poisonous materials" from hands, Semmelweis chose chlorinated lime. In May 1847, he required the students and doctors entering the First Division to wash their hands in this solution. Later this practice was made compulsory, as was the washing of hands before each examination.

The results were astounding (Figure 2, $B$ ). The death rate declined dramatically and, in 1848 , the first complete year with full implementation of hand washing, it was only $1.27 \%$ — an unprecedented record. As Semmelweis celebrated this achievement, few took him seriously. His colleagues and many superiors ridiculed the outrageous extravagances of chlorinated lime water, and the medical students grumbled at the frequency of hand washing; those currying favor from Professor Klein even sabotaged the disinfection efforts.

From this time onward, Semmelweis seemed to be haunted by misfortune. His biannual contract was not renewed in 1849; he fled to Pest and joined the university there. Even here, his doctrine was not well received. Although he presented his findings on puerperal sepsis at the Viennese Medical Society in 1850, he did not publish them until $1861^{5}$ (Figure 1). This book was also dismissed by the skeptics and ignored by scholars, partly because of its long, rambling passages and confusing writing style, and partly because of the combative spirit of its author. Angered by the poor reception of his theory, Semmelweis published scathing, "open letters" to professors identifying them by name, and declaring them as "medical Neros" and "murderers."

The final years of Semmelweis' life were miserable. According to recent research, he probably developed Alzheimer's presenile dementia - a condition causing severe psychological symptoms, including bouts of depression and euphoria. ${ }^{4}$ In July 1865 , he was committed to an asylum in Vienna, where he died 2 weeks later. Although popular biographers have stated that septicemia ${ }^{2,3}$ similar to the childbed fever he had battled against, was the cause of his death, historian Nuland concludes that Semmelweis probably died from the effects of severe beatings received while in asylum — a sad, but rather common practice in such facilities in those days. ${ }^{4}$

\section{Neonatal Sepsis and Its Role in Semmelweis' Path to Discovery}

Within the first few months of starting his work at the Lying-in-Hospital, Semmelweis studied both the maternal and newborn mortality patterns. Kolletschka's death and his autopsy findings indeed provided him with the final piece of the puzzle to solve the riddle of childbed fever; but it was the fetal and neonatal mortality, along with newborn autopsy findings that provided crucial links to his eventual discovery. The following excerpt is from his discussion on the prolonged first stage of labor due to delayed cervical dilation as a risk factor for childbed fever:

\footnotetext{
"All parturients, in whom the dilatation period is prolonged ... [for] 24, 48 hours and over, almost without exception became ill ... and died of childbed fever [in the First Division, not in the Second] ... even their newborn children, whether male or female, have all died of puerperal fever....
} 

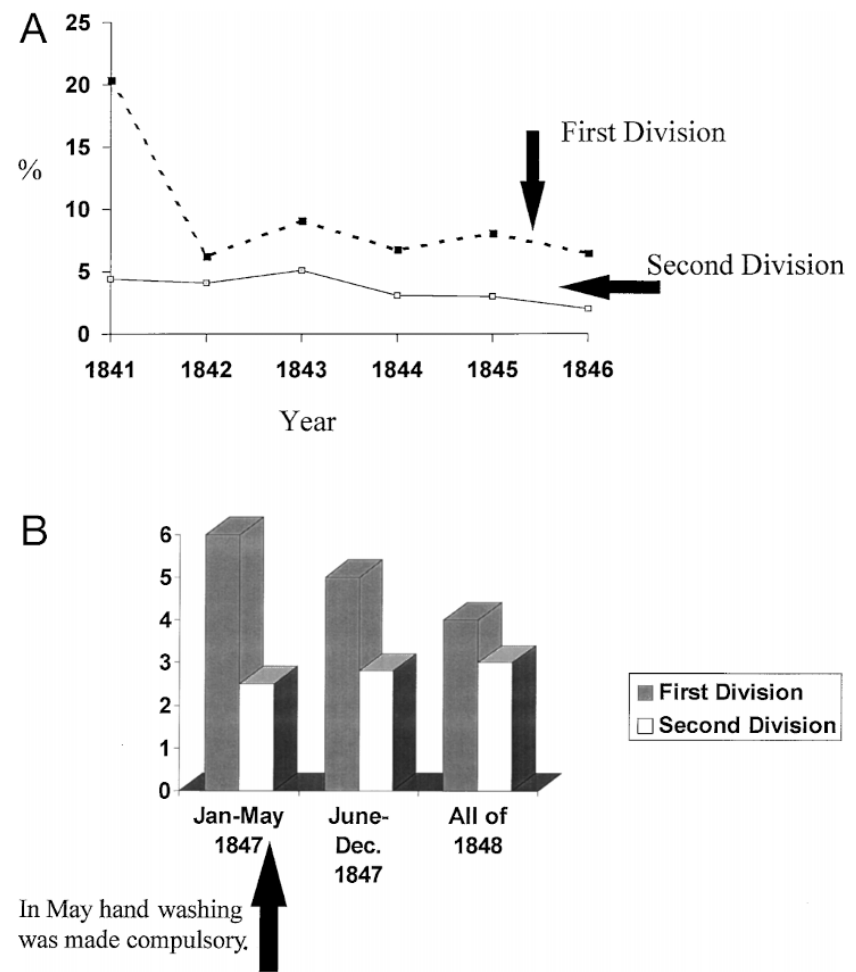

Figure 3 Newborn infant mortality from childbed fever in the two divisions of the Lying-in-Hospital before the introduction of routine hand washing (A) and after (B).

The anatomical findings in the cadavers of such newborn were ... identical with findings in the dead bodies of [the victims of] ... puerperal fever. ... To recognize these findings and ... to reject [a common etiology] ... is to reject pathological anatomy. If it is one and the same disease from which the puerperae and the newborn die, then there must be the same etiology for the newborn [as that] applies to the mothers. ... In the First Division, the newborn [s] also die in much larger numbers than in the Second."

The true death rate was probably even higher than shown in Figure $3 A$ for the First Division: Some infants were transferred to the Foundling asylum because of their mothers' illness or death, and their outcome data were not included in the statistics. These observations prompted Semmelweis to question the prevailing theories of childbed fever, such as atmospheric pollution, mother's "fear of death" during labor, "injured feminine modesty" from exposure to male doctors, and being in labor ("puerperal state"). Because none of these explained "puerperal infections of the newborn," the theories must be wrong, he argued; therefore, a common cause must be sought to explain the illnesses.

How does a prolonged first stage of labor relate to the observed findings? Semmelweis provides an explanation. ${ }^{7}$ As a routine, after their autopsy duties, assistant physicians made rounds in the morn- ing, examining women in labor (they wore no gloves!). Then the professor accompanied the students on rounds and, as part of the instructions, the professor would perform a vaginal examination, and let each student repeat it. Therefore women with prolonged labors were getting examined several times a day, by "hands contaminated by cadaveric particles," whereas, those with a normal or preterm labor (the latter were not to be examined) were spared from such repeated examinations and spared thus from the risk of childbed fever.

While brooding over the above observations, Semmelweis encountered the autopsy findings of Kolletschka that was to lead him to develop a comprehensive theory for the etiology of childbed fever in the mother and the newborn infant:

"The first principle is the absorption of the decomposed animal organic substance [by women in labor through the cadaveric particles from the bands of doctors and medical students] ... as a result of this ... there is ... a change in composition of the blood. [These changes] ... occur at a time

during which the fetal blood is in organic communication with the maternal blood-stream; as a result, a change in the composition of the blood from which the mother suffers is transmitted to the infant. As a result we see the newborn [s], male or female, die from a disease ... identical with that of the mother, ... just as frequently as do the mothers in the First Clinic, and more frequently than do the newborn [s] in the Second Clinic... [When] the infant, yet unborn inside the genital organs, is contaminated during the examination by a finger infected by cadaveric particles, ... childbed fever occurs in the newborn because ... its blood comes in contact through the placenta with the maternal blood already polluted as a result of the absorption of decomposed animal-matter [from the contaminated fingers of doctors].

"The occurrence of childbed fever among the newborn can be explained in two ways. [It] may be caused by factors operating on the mother during intrauterine life of the fetus, and the mother can then impart the disease on the infant.

"Alternatively, the cause may affect the infant itself after birth, in which case the mother may or may not be affected. Thus the infant dies, not because the disease has been imparted, as in the first case, but rather because childbed fever originates in the infant itself. "Therefore, ... if [childbed fever] is communicated to it by way of the mother's blood, both fall sick... only if the infant is still in organic

communication with the mother by way of the

placenta... The mother can become ill from childbed fever and the child can remain bealthy [if] 


\section{the organic communication between the mother and child are interrupted at a time during labor [when] disintegration of the maternal blood has not yet set in...."}

The above excerpts clearly show that Semmelweis developed three interrelated, logical concepts concerning maternal and neonatal infections: (1) Because of identical clinical course and autopsy findings, childbed fever affecting the mother and the infant must be one and the same; therefore, this disease is not peculiar to only puerperal women; (2) Even if the existing theories can explain maternal disease, they cannot explain fetal and newborn diseases; therefore the theories must be wrong, and new etiological explanations must be sought; and (3) The theory that "cadaveric particles" transmitted via the dirty hands of doctors and medical students causes childbed fever should be true: This leads to maternal "blood disintegration" and subsequent fetal infection, only if the polluted maternal blood can still come in contact with the fetal blood. If the newborn is infected postnatally, the mother may remain healthy.

It is quite remarkable that Semmelweis made these seminal observations before the bacterial etiology of infectious diseases was discovered. Although it was known that diseases such as smallpox and malaria can affect the fetus via the mother, Semmelweis appears to be the first to provide a sophisticated explanation for the pathogenesis of fetal infection through the hematogenous route via the placental circulation.

Semmelweis was much ahead of his time and few could have understood his doctrine and its implications. While many prominent scientists agreed with him, many equally prominent scientists, such as Rudolf Virchow, honestly disagreed with him, insisting that additional causes must be sought to explain childbed fever; Semmelweis could not find objective and dispassionate means of convincing such skeptics. His paranoid approach to quelling his opponents and his inflam- matory language further enhanced opposition to his ideas. Sadly, he died young and could not see his doctrine vindicated by luminaries such as Louis Pasteur and Joseph Lister.

Semmelweis was no saint. His was a tortured soul, with a dream fueled by a fiery temperament. Clearly, his discovery saved thousands of women in his own time, and he deserved all of the accolades that came later. Albeit belated, the elucidation of the mechanism of fetal infection should be included in the list of accomplishments of this troubled, unfortunate genius.

\section{Acknowledgments}

My sincere thanks to Dr. Kristine M. McCulloch for help during the preparation of this manuscript. I also thank the Classics of Medicine Library, Birmingham, AL, for permission to reproduce excerpts and Figure 1 from Semmelweis' book.

\section{References}

1. Strauss MB. Familiar Medical Quotations. Boston: Little Brown \& Company; 1968. p. 108.

2. Bender GA. Semmelweis: defender of motherhood. In: Bender GA, editor. Great Moments in Medicine. Detroit: Northwood Institute Press; 1966. p. 198-207.

3. Gortvay Gy, Zoltán I. Semmelweis: His Life and Work. Budapest: Akademiai Kiado; 1968. p. 15-35.

4. Nuland S. The germ theory before germs: the enigma of Ignác Semmelweis. In: Nuland SB, editor. Doctors: The Biography of Medicine. 2nd Ed. New York: Vintage Books; 1995. p. 238-62.

5. Semmelweis IF. The Etiology, the Concept and the Prophylaxis of Childbed Fever Together with the "Open Letters." Nuland SB, Gyotgyry FA, editors. Birmingham, AL: The Classics of Medicine Library, 1981. p. 351-353.

6. Semmelweis IF. The Etiology, the Concept and the Prophylaxis of Childbed Fever Together with the "Open Letters." Nuland SB, Gyotgyry FA, editors. Birmingham, AL: The Classics of Medicine Library, 1981. p. 381-3.

7. Semmelweis IF. The Etiology, the Concept and the Prophylaxis of Childbed Fever Together with the "Open Letters." Nuland SB, Gyotgyry FA, editors. Birmingham, AL: The Classics of Medicine Library, 1981. p. 401-3. 